\title{
Education Organization Models that Enhance the Success of Students with Special Needs
}

\author{
France Dubé, Chantal Ouellet, Mirela Moldoveanu, \\ Marie-Eve Gadbois and Marie-Jocya Paviel \\ University of Quebec at Montreal, Canada
}

\begin{abstract}
This synthesis of knowledge focuses on the best practices and seeks to answer the question: What are the most effective service organization models to promote access, retention, and the academic success of students with disabilities or special needs? Our findings have identified certain courses of action that would make more effective the service organization models in educational institutions. The most promising models identified in all levels of education, involve collaboration among the teachers and the rest of the educational staff, in contexts where the services are integrated into the regular school system.
\end{abstract}

\section{Introduction}

Some general organization models are known and can be implemented in educational institutions; 'mainstream' integration is still very present, but some institutions have made attempts for full inclusion. This context influences the services offered to targeted students, but how do education institutions organize the services to better respond to the needs of learners with disabilities or special needs?

\section{Core Issue}

Several instances propose orientations and an organizing framework. Educational institutions are responsible for service organization and services are often decentralized to these institutions resulting in a wide variability of the services offered. This synthesis of knowledge focuses on the best practices and seeks to answer the following question: What are the most effective service organization models to promote access, retention, and the academic success of students with disabilities or special needs?

\section{Conceptual Framework}

The organization of one or several classes could be considered for all students while intensifying the interventions for students with difficulties once differentiated instruction is introduced. Other researchers have studied dropout prevention models that promote retention; models where there was a teacher and a learning specialist in the same class or where two teachers were responsible for the same group.

Some others have focused on the effects of the combination of several classes. And still some others have studied models for dropout prevention that enhance retention and certain types of educational service organizations that can be implemented such as the Response to Intervention Model.

Other models that can also be implemented are the teaching and co-teaching teams that gather a teacher and a learning specialist in ordinary classes, or even the flexible grouping or several classes can be regrouped. In this research, the objectives to be achieved are to:

1. Map the models of services available intended to encourage the access, retention, and success of students with disabilities or special needs.

2. Analyze the effects reported by the researchers of the service organization models that help students' succeed.

3. Present the models favoring success and determine how these models could be transferred to other institutions.

This research analyzes the service organization models with regard to the administrative, educational, and systemic aspects, considering the organization within one or more educational establishments and where prevention is promoted.

\section{Methodology}

Our corpus is composed of empiric qualitative and quantitative researches coming from 15 countries; all of them were published during the last 10 years.

A first review of scientific literature has allowed us to identify 12647 texts. In order to select those who would contribute best to achieving our research objectives, the members of the research team read summaries of these writings and sorted them.

In the course of our review, we identified 960 scientific studies that were submitted to a transversal reading by two research assistants and three professors/researchers in order to establish their relevance to the research objectives and the inclusion 
criteria. To reach an agreement, abstracts were rated as follows: 1. Fully meets the objectives 2 . Partially meets the objectives 3 . Does not meet the objectives. All of the three professors/researchers rated the tests separately. Only scientific texts having obtained 3 times the score 1 were analyzed for this synthesis of knowledge; 85 were finally selected for analysis. From this corpus, they identified 26 texts on preschool and primary school, 29 on secondary school, and 10 on post-secondary school (higher education, universities, vocational training). Eight of them were from Canada, 55 from the United States, 16 from Europe (eight from the United Kingdom, one from Italy, one from Switzerland, one from the Netherlands, one from Finland, one from Austria, one from Ireland, one from Greece and one Europe multi-country), four from Australia, two from Israel, and one from Kuwait. In addition, 65 dealt with potential effects on students, while other 20 discussed potential effects on educational practices.

A mixed analyze method was applied followed by an inclusive final synthesis [8]. Thereafter, they analyzed the service organization models with regard to the administrative, educational, and systemic aspects, considering the organization within one or more educational establishments where prevention is promoted.

The analysis method favored is the narrative review, an interpretative analysis technique adapted both for data of quantitative and qualitative nature [13]. The analysis was performed with NVivo.

In essence, this paper will discuss research papers on inclusive organizational models from preschool to post-secondary school.

\section{Results}

The results of this synthesis of knowledge are presented in relation to the six following areas: prevention, administrative factors, systemic factors, transitions, pedagogical background and information and communication technologies.

\subsection{Prevention}

The review on studies that examine prevention shows that the implementation of heterogeneous groupings from kindergarten had positive effects on the most vulnerable students. Researchers [7] compared the effects of the classroom composition on the emergence of school competences comparing preschool and kindergarten programs of targeted groups and mixed groups. Preschool students in inclusive classroom settings have progressed more than those who followed programs targeted by the emergence of mathematical competences, while those following the inclusive program since kindergarten had progress more than the targeted groups both in reading and in mathematics. These results could be explained, among other reasons, by the possibility students at risk would have to make exchanges with classmates that have a more elaborate vocabulary and ease of expression.

Harding et al. [9] developed an after school tutoring model for primary schools in disadvantaged areas. It was offered individually, in sub-groups, with a computer, or a combination of the three. This program showed positive effects and a significant correlation between the number of tutoring hours and the results in mathematics and the language of instruction. Even though most students benefited from a combination of these supports, it is those that benefited from tutoring in subgroups that progressed the most. The authors found that the number of hours spent in tutoring would have an impact on the results and that those having benefited from the help in subgroups were those that had progressed the most, both in reading and mathematics. We can thus conclude, based on these studies, that interacting with pairs has an impact on the success of students with special needs.

\subsection{Administrative Factors}

The analysis of papers on service organization in the regional resources and the school districts shows that the collaboration among all school stakeholders is important. The integration of regular teaching with differentiated teaching is continually expanding in the United States of America where teachers are asked to work together in an effort to improve the learning opportunities for all students. Two secondary schools have chosen to include all students with special needs in the general educational system [14]. To make this project viable, managers and teachers reorganized both the teachers' tasks and the students' schedules. They also accompanied the professional development of the stakeholders taking part in the project based on scientific literature research that talked about inclusion, strategies to modify and differentiate instruction, co-teaching models and strategies, and ways to work effectively with students with specific disabilities and special needs. Children with mild to moderate learning difficulties that attended these schools said they preferred an all-inclusive structure. Moreover, the teachers reported that students worked more when faced to the challenges of general education. By doing so, students with special needs, were confronted to great challenges, and would make further progress. However, the stakeholders said that the more severe the difficulties or handicaps were, the more difficult it was for the student to be included in the general system.

Two approaches are intended for school managers to contribute to the development, implementation, use, and assessment of pedagogical practices that have empirically proven to be the most 
effective at secondary school [2]. The first one is to re-orient their role from managers to real pedagogical leaders. The second is on key strategies and the enhancement of pedagogical practices and educational organisation services for students with special needs or handicaps. A collaborative relationship must also be established and pedagogical priorities must be elaborated and adopted by all stakeholders. When administrators make decisions based on research knowledge and use the results of empirical studies to solve the educational problems; they enhance the potential effectiveness of learning conditions because they encourage and support teachers to adopt quality teaching practices and face the challenge of transforming the duality special education - general education by offering a continuum of practices that have proven to be effective for students with special needs, but also to all the students entrusted to them.

The collaboration between the school, the community, the parents, the social services, and the health services is of critical importance [19]. The authors recommend that collaboration efforts should be intensified particularly during school transitions. In fact, they have studied the mechanisms that should be instituted among all stakeholders to create a closer and more participatory collaboration among the healthcare network, the social services, and the education services. By acknowledging the importance of collaboration practices between all stakeholders and managers, they would allocate to it more time. It is clear that, the more the networks interact with each other, the more the services and the roles become clarified. In this regard, the participation of the parents is pursued. Parents are able to identify key moments of transition (e.g., transition from daycare to primary school) as specific moments when collaboration should be a priority, given all the issues at stake related to the child needs. Three recommendations are made to the managers:

1. To inform parents about the services offered by both services with the help of a tailored-made documentation.

2. To get parents more involved regarding the integrated continuum of services -to guide them, seek their presence, take into account their opinion and their expertise.

3. To experiment and document innovative approaches to foster both parental and students' involvement.

They recall the importance for representatives of both networks to define and provide leadership. They should support collaborative actions, assist parents, and be proactive rather than reactive to children's difficulties.

This collaboration and management support will in turn also contribute to a better service organization and improve the communication among the teaching staff, the support teaching staff, the education managers, and the school principals [2]; as well as it eases the gap between regular teaching and differentiated teaching [6] [14].

\subsection{Systemic Factors}

Studies focusing on the organization of services argue that the adoption of a universal model that contributes to the inclusion of all children reducing barriers to learning for all students, including those with special needs would increase students' academic success. Researchers [17] have studied the effects of heterogeneous grouping on the success and the motivation of students with special needs. They found that positive results were observed among students with difficulties, whereas no effects were observed in students without difficulties. Given the significant gains attained by students with special needs in terms of success and motivation, they recommend primary school teachers to organize heterogeneous groups as often as possible. Another model promoted the organization of preschool using a "universal" model that aimed at all students, whether with difficulties or not, and where all stakeholders are responsible for all groups of students who are offered writing, mathematics and language acquisition activities. [7] This organization model then continues in kindergarten; alternating activities in large groups, followed by activities in sub-groups. Results show that this universal approach is more successful, thus leading to significant literacy and mathematics gains, compared to special kindergarten classes where students are divided according to their difficulties from the very beginning.

To establish a link between the regular and adapted schools [6] researchers studied two schools, one in Ireland and one in England. These schools stress the collaboration between the regular and the special education schools. They coordinate the teaching/learning activities, the curriculum, the collaboration, and the learning specialists to stay as close as possible to the regular national program while being flexible and responsive to the individual needs of students with special needs. The tie created between the two types of schools is highly valued and stakeholders are present to share their expertise.

While observing a support team-based model in an inclusive teaching context, researchers have identified a few key elements for the support to be more effective: a teacher support team, an effective implementation, a monitoring plan of action, and bimonthly monitoring. [20] The most remarkable effects were observed among participating teachers. Out of 48 specialists who worked with students with Autism Spectrum Disorders (ASD), 93\% of them argued that the teaching support team has actually provided them a real support and $91 \%$ said that it increased the self confidence of mainstream teachers 
working with ASD students. Having a support team to help them meet the needs of students with difficulties integrated into regular classes, help the participating mainstream teachers of our study feel better equipped, more confident, and well supported to meet the needs of students with ASD. The teaching staff says they have noticed academic, social, behavioural, and socio-affective and emotional progress among targeted students. The results pave the way to integrate services for all students at risk included in regular classrooms.

\subsection{Transitions}

Studies on education transitions recall the importance of the collaboration among early childhood workers to adequately prepare the children to enter kindergarten. Among very young students, a successful transition may be related to several factors including individual characteristics of the child, difficulties or disabilities, the family's ability to participate in the transition, the surrounding community -available resources and the values conveyed to the child development. A service organization that facilitates school transitions comprises collaboration among early childhood stakeholders, the school board, and kindergartens. Additionally, it envisages a system of gradual changes where families whose children will live the transition between early childhood and tailored early intervention services are supported [3]. They propose three successive stages to ease the transition:

1. The child is in the same class and enjoys the same services, but a different provider offers them.

2. The child faces a transition to a program associated to the one already followed.

3. The child compromises to its new educational environment.

According to the authors, effective transition practices would prepare the child to adjust himself to the new learning environment in minimum time with maximum benefits. A transition would be considered successful when the child is able to interact positively with adults, peers and the school equipment in the new learning environment.

To help students with special needs be prepared to follow a post-secondary education, researchers [15] have studied the effects of academic learning success during secondary school in groups of post secondary students with learning disabilities receiving appropriate services. Three conditions were observed: follow an academic learning success course, benefit from an individual follow-up (highintervention), or an occasional follow-up (lowintervention). Participating students were invited to use all the services available for students with special needs such as strategic learning tools, academic coaching and counselling, sessions on strategic learning abilities, and assistance in the use of technology. All academic support services focus on the academic and compensatory skills necessary for the students' successful completion of their programs. A comparison between the pre-test and post-tests show that students following the academic success course as well as those who received regular individual follow-up had improved their academic self-efficacy scores and they used better the academic resources. The authors emphasize that these two devices help contribute to the retention and the success of students with special needs, however, the courses of academic learning successfully completed would be particularly effective when they were specifically oriented to learning content related to an specific training program and the skills required to succeed it.

\subsection{Pedagogical Background}

This point covers the class organisation and the organization among the groups of students in certain inclusive models where students with special needs are offered supplementary support sessions.

A research has also examined a supplementary support session -the class liaison- where specialized teachers were responsible to meet some of the specific learning needs so that all students remain in regular classes [11]. This support model has had positive effects on the academic achievements of the integrated students and on the teaching practices.

A study was launched for the development of an assessment model of an inclusive education support system using pedagogical reinforcement via the principles of coeducation and the collaboration of regular and specialized teachers. [1] The pedagogical Reinforcement postulates a co-construction of adapted pedagogical responses with the regular teacher while it also resorts to the co-teaching. This approach would contribute to the development of positive attitudes and a sense of high self-efficacy, which would support and motivate teaching practices that promote inclusion, and increase the chances of success; a success that, in turn, encourages the attitudes and the self-efficacy as it reinforces the culture established at the institution.

Some others [12] studied a model where the regular classroom teacher and the specialist were working together as partners in the same class. In this model, the regular teacher, depending on each content, was more responsible for its teaching, while the specialist would offer support and mostly concentrate on the learning strategies useful for the specific content being taught. Depending on the subject, the difficulty it pose and the following tests, they would determine which teacher would be in charge of the pedagogical activity.

A Content Mastery Center [10] model could be offered to students with special needs in regular 
classes. This model would replace the support model where special help is offered outside the classroom. Thus making it possible for children with exceptional challenges to learn alongside other students. Students with difficulties and at risk can participate in all classroom activities while they have the possibility of visiting the Center whenever they need additional support. Also, every time they experience any difficulty whatsoever, they can consult the Center, avoiding both falling behind and the need to be referred to the teaching specialist. The implementation and success of this organizational model greatly depends on the collaboration established between the teachers and the head of the Centre. The study shows that at risk students and students with learning difficulties who profited from this model have appreciated this type of support and have progressed more at school. Significant correlations were found between the time the students spent at the Center and their school performance. Most students that profited from the Center support were promoted to the following grade year after year.

A Peer-assisted Learning Strategies (PALS) model implemented for the whole class at several school levels [16] could also be proposed. The activities include peer reading, story telling, paragraph synthesis, and making predictions. Students in special classes, whether having or not intellectual deficiency, saw their performance and reading comprehension skills improved. Other authors [17] studied the effects of grouping the students with special difficulties integrated in regular classes according to their performance and their motivation. They stated that heterogeneous groupings had positive effect on students with difficulties. Taking into account the significant success and the motivation gains of the students with special needs, they recommend primary school teachers to organise heterogeneous groups as often as possible.

\subsection{Information and communication technologies}

This last heading presents a few papers we have reviewed on how the information and communications technology could contribute to the success of learners with special needs. Researchers [5] studied the development of a mobile application that would support students with special needs in their transition from primary to secondary school. It is designed so that children with special difficulties from all backgrounds can have access to it. It is adapted to students in regular classes, in special classes, and even studying at home. It is developed to meet certain needs such as organization, relationship with peers, and it includes interactive quizzes. It also allocates students personal information spaces for storing all their own information in connection with the classes or the teachers. It can also be used with the parents or the teachers' help during a transition period.

At post-secondary level, [4] it would be possible to offer an accommodation and support model that makes online promotion on the web conceived to make the services more accessible. They are known for contributing to teaching, assessment and campus life. It also gives students access to interpreters, offers video calls for the deaf, and a service of note taking. Positive results prompted the authors to suggest that this service model should also be implemented at secondary schools to support students' with sensory impairments learning. Furthermore, it would contribute towards the transition to the post-secondary education.

Researchers [18] have also studied a model from a Florida University where a website was developed to contribute to an inclusive approach and disseminate information on post-secondary studies making accessible all the services available. It was offered to all the special need students. This accessibility and visibility lead to a better use of the accommodations put into service to enhance their academic success.

\section{Discussion}

Our findings have identified certain courses of action that would make more effective service organization models, including an inclusive approach [20], [10] entailing collaboration of all the parties involved [2], [19], [3]. Others try to make more visible the services that are already offered [4]; [18] and help the students make a better use of the services they are offered [15]. Integrating the regular and the adapted systems [6], [11], [14] and maximising the opportunities of interaction with their pairs would entail academic success [7], [16], [17].

\section{Conclusion}

However, it is clear that there is need for further research to investigate the question of the effects of the service organization models on retention and success rate for students with special needs.

Studies examining the effectiveness of inclusive educational models involving collaboration among the different actors as well as researches on coteaching would be promising scientific contributions to organize the teaching/learning process of several groups of students with special education needs.

In the light of the scientific texts identified in this synthesis, concentration among the different administrative levels that work in the organization of 
service models to support access, retention and success of students with special needs or disabilities has not yet been the object of empirical studies. Some authors give advices regarding the development of a real pedagogical leadership at administrative level; however, we believe it is important to recommend that their decisions are to be supported by the data from recent research rather than financial considerations, if decision makers sincerely want to have positive effects so that these students actually graduate.

Lastly, according to several studies, for the teachers to adopt pedagogical practices having shown to be effective, they need training and support. We emphasise the importance of establishing continuing education programs and workshops to help address the need for renewal and the adoption of effective practices focussed on the access, retention, and success of the greatest number of learners possible.

Our synthesis of knowledge has brought to light that there are very few researches that deal with effective practices in the administration and management of services that contribute to the access, retention, and success of students with special needs. Additionally, several researches describe service organization models, but some other research needs to be conducted to evaluate the effects to the access, retention, and success of students with special needs or with disabilities.

Further research is also needed to determine the effects of co-teaching on students' success and to evaluate the effects of the use of Tic on the access, retention and success of students with special needs. The models of flexible and differentiated instruction for students with special needs in the inclusion context should also be further analyse. There is also a need to describe collaboration practices involving school directors, administrators and managers as well as their effect on the organisation of effective services. Finally, there is a need to develop support models and teacher training models and workshops on collaborative and inclusive classroom practices.

\section{Acknowledgements}

We wish to thank the Social Sciences and Humanities Research Council of Canada (SSHRC) for the financial support they provided so that this research project may be completed.

\section{References}

[1] Bonvin, P., "Développement d'un modèle d'évaluation d'un dispositif de soutien à l'inclusion scolaire", Education et francophonie, 39(2), (2011), pp.250-271.
[2] Boscardin, M. L., "The administrative role in transforming secondary schools to support inclusive evidence-based practices", American Secondary Education, 33(3), (2005), pp. 21-32.

[3] Branson, D. M. and Bingham, A., "Using interagency collaboration to support family-centered transition practices", Young Exceptional Children, 12(3), (2009), pp. 15-31.

[4] Cawthon, S. W., Nichols, S. K. and Collier, M., "Facilitating access: What information do Texas postsecondary institutions provide on accommodations and services for students who are deaf or hard of hearing? " American Annals of the Deaf, 153(5), (2008), pp.450-460.

[5] Chambers, D. and Coffey, A., "Development of a mobile-optimised website to support students with special needs transitioning from primary to secondary settings", Australasian Journal of Special Education, (2013), pp.7991.

[6] Day, T., Prunty, A. and Dupont, M., "Responding to students' needs in special schools in Ireland and England: Findings from two schools", Journal of Research in Special Educational Needs, 12(3), (2012), pp.141-150.

[7] de Haan, A., Elbers, E., Hoofs, H. and Leseman, P., "Targeted versus mixed preschools and kindergartens: Effects of class composition and teacher-managed activities on disadvantaged children's emergent academic skills", School Effectiveness and School Improvement, 24(2), (2013), pp. 177-194.

[8] Harden, A., "Mixed-Methods Systematic Reviews: Integrating Quantitative and Qualitative Findings", Focus, Technical brief 25, (2010). National Center for the Dissemination of Disability Research.

[9] Harding, H. R., Harrison-Jones, L. and Rebach, H. M., "A study of the effectiveness of supplemental educational services for title I students in baltimore city public schools". The Journal of Negro Education, 81(1), (2012), pp.52-66.

[10] Jenkins, A., "Restrictiveness and race in special education: The content mastery center model" Learning Disabilities: A Contemporary Journal, 3(1), (2005), pp.4550.

[11] Lapointe, J.-R. et Dion, J., "Description d'un processus de théorisation portant sur les conditions de réussite d'une expérience d'inclusion vécue par des élèves en troubles d'apprentissage: Pratiques éducatives, attitudes parentales et éléments contextuels ", Approches inductives: Travail intellectuel et construction des connaissances, 2(1), (2015), pp.68-91.

[12] Mastropieri, M. A., Scruggs, T. E., Graetz, J., Norland, J. et al., "Case studies in co-teaching in the content areas: Successes, failures, and challenges", Intervention in School and Clinic, 40(5), (2005), pp.260270. 
[13] Petticrew, M. and Roberts, H., Systematic reviews in social sciences: a practical guide. (2005). Malden: Wiley Blackwell.

[14] Pierson, M. R., and Howell, E. J., "Two high schools and the road to full inclusion: A comparison study", Improving Schools, 16(3), (2013), 223-231.

[15]Reed, M. J., Kennett, D. J., Lewis, T., Lund-Lucas, E., Stallberg, C. and Newbold, I. L., "The relative effects of university success courses and individualized interventions for students with learning disabilities", Higher Education Research \& Development, 28(4), (2009), pp.385-400.

[16] Sáenz, L. M., Fuchs, L. S. and Fuchs, D.,"Peerassisted learning strategies for english language learners with learning disabilities", Exceptional Children, 71(3), (2005), pp.231-247.

[17] Saleh, M., Lazonder, A. W. and De Jong, T., "Effects of within-class ability grouping on social interaction, achievement, and motivation", Instructional Science: An International Journal of Learning and Cognition, 33(2), (2005), pp.105-119.

[18] Smith, T. J. and Benito, N., "Practice brief: Florida college collaborative--facilitating inclusive postsecondary education opportunities for youth with intellectual disabilities", Journal of Postsecondary Education and Disability, 26(4), (2013), pp.395-402.

[19] Tétreault, S., Beaupré, P., Carrière, M., Freeman, A., Gascon, H. et Marier Deschênes, P., "Déficience, scolarité, parentalité: Comment s'organise la complémentarité des services?", Revue francophone de la déficience intellectuelle, 23, (2012), pp.5-12.

[20] Trépanier, N. et Labonté, M., "Un modèle d'équipe de soutien à l'enseignant pour offrir des services intégrés en contexte inclusif ontarien: Le cas d'élèves présentant un trouble du spectre de l'autisme", Revue francophone de la déficience intellectuelle, 25, (2014), pp.131-147. 